CASE REPORT

\title{
Functional characterization of a rare germline mutation in the gene encoding the cyclin-dependent kinase inhibitor p27Kip 1 (CDKN1B) in a Spanish patient with multiple endocrine neoplasia-like phenotype
}

\author{
Donatella Malanga $^{1,2}$, Silvia De Gisi ${ }^{2}$, Miriam Riccardi ${ }^{1,2}$, Marianna Scrima ${ }^{2}$, Carmela De Marco ${ }^{1,2}$, \\ Mercedes Robledo ${ }^{3}$ and Giuseppe Viglietto ${ }^{1,2}$ \\ ${ }^{1}$ Dipartimento di Medicina Sperimentale e Clinica 'G Salvatore', Università Magna Graecia, Campus Universitario Germaneto, 88100 Catanzaro, Italy, \\ ${ }^{2}$ BIOGEM-Istituto di Ricerche Genetiche 'G Salvatore', 83031 Ariano Irpino (AV), Italy and ${ }^{3}$ Hereditary Endocrine Cancer Group, Human Cancer \\ Genetics Programme, Spanish National Cancer Centre, Centro Nacional de Investigaciones Oncologicas (CNIO), Calle Melchor Fernandez Almagro 3 , \\ 28029 Madrid, Spain
}

(Correspondence should be addressed to G Viglietto at Dipartimento di Medicina Sperimentale e Clinica 'G Salvatore’ Università Magna Graecia; Email: viglietto@unicz.it)

\begin{abstract}
Objective: The aim of this study was to investigate the presence of germline mutations in the CDKN1B gene that encodes the cyclin-dependent kinase ( $\mathrm{Cdk}$ ) inhibitor p27 in multiple endocrine neoplasia 1 (MEN1)-like Spanish index patients. The CDKN1B gene has recently been identified as a tumor susceptibility gene for MEN4, with six germline mutations reported so far in patients with a MEN-like phenotype but negative for MEN1 mutations.

Design and methods: Fifteen Spanish index cases with MEN-like symptoms were screened for mutations in the CDKN1B gene and the mutant variant was studied functionally by transcription/translation assays in vitro and in transiently transfected HeLa cells.

Results: We report the identification of a heterozygous GAGA deletion in the $5^{\prime}$-UTR of CDKN1B, NM_004064.3:c.-32_-29del, in a patient affected by gastric carcinoid tumor and hyperparathyroidism. This deletion falls inside the region that is responsible for CDKN1B transcription and is predicted to destroy a secondary stem and loop structure that includes the GAGAGA element responsible for ribosome recruitment. Accordingly, in vitro studies of coupled transcription/translation assays and transient transfection in HeLa cells showed that the GAGA deletion in the CDKN1B $5^{\prime}$-UTR significantly impairs the transcription of downstream reporter luciferase (of $\sim 40-60 \%$ ) and, possibly, the translation of the corresponding mRNA. This mutation was associated with a significant reduction in the amount of $C D K N 1 B$ mRNA in peripheral blood leukocytes from the patient, as demonstrated by quantitative real-time PCR.

Conclusions: Our results confirm that germline CDKN1B mutations may predispose to a human MEN4 condition and add novel evidence that alteration in the transcription/translation rate of CDKN1B mRNA might be the mechanism implicated in tumor susceptibility.
\end{abstract}

European Journal of Endocrinology 166 551-560

\section{Introduction}

Multiple endocrine neoplasia (MEN) syndromes represent autosomal dominant disorders characterized by the occurrence of tumors in two or more endocrine glands. So far, two MEN syndromes have been well recognized: MEN type 1 (MEN1), caused by germline mutations in the MEN1 tumor suppressor gene, and MEN2, caused by germline mutations in the RET protooncogene respectively. Recently, Pellegata et al. (1) identified a novel MEN-like syndrome in rat, denoted MENX. Animals affected by MENX spontaneously develop multiple endocrine tumors, with symptoms that overlap both human MEN1 and MEN2. Genetic studies in the rats predisposed to MENX identified a loss-of-function germline mutation in the $C d k n 1 b$ gene that encodes the cyclin-dependent kinase (Cdk) inhibitor p27 as the causative mutation for the MENX syndrome (1). Subsequently, mutations in the human homolog CDKN1B gene were identified in patients with multiple endocrine tumors that were negative for MEN1 or RET mutations $(2,3,4)$. As a consequence of these observations, a novel human MEN-like syndrome, caused by germline mutations in CDKN1B, was recognized as a separate disease and denoted MEN4 (5). 
P27 is an inhibitor of Cdks that negatively regulate cell cycle progression in mammalian cells. Loss of p 27 protein expression has been reported as a frequent event in human cancers $(6,7)$. Importantly, reduced p27 expression in cancer cells is correlated with tumor aggressiveness, invasion, and poor differentiation, predicting shorter disease-free and/or overall survival $(7,8$, $9,10,11)$. Yet, CDKN1B does not fit all classic features of a tumor suppressor gene, since it is rarely mutated in cancer $(12,13,14)$. Point mutations in the coding region of CDKN1B are rare $(12,15,16)$ and loss of heterozygosity has been observed only in some tumors $(16,17,18)$. Therefore, alternative mechanisms that act at the posttranscriptional or post-translational level have been suggested. These alternative mechanisms include a lower translation rate of CDKN1B mRNA (19), an increase in protein degradation $(20,21)$, and the cytosolic mislocalization of p27 protein $(22,23,24)$.

Importantly, experiments with $C d k n 1 b$-deficient mice have established that $C d k n 1 b$ is a haploinsufficient tumor suppressor gene. Both Cdkn1b-null and heterozygous mice are predisposed to spontaneous pituitary adenomas $(25,26,27)$, as well as to radiation- and ethylnitrosourea-induced tumors in multiple tissues (28).

In this study, we report on the identification of a germline mutation in the $5^{\prime}$-UTR of CDKN1B, corresponding to the deletion of four nucleotides GAGA centered at position -27, NM_004064.3:c.-32_-29del, in a patient with multiple endocrine tumors showing MEN1-like phenotype. In vitro functional assays demonstrated that the c.-32_-29del in the 5'-UTR of CDKN1B gene can account for the reduced expression of p27 mRNA in patients affected by MEN-like syndrome.

\section{Materials and methods}

\section{Patients}

Each index case (proband) had been previously referred for MEN1 genetic screening. Only one of them presented familial antecedents related to the disease at the moment this study was performed (Table 1). Written informed consent to collect phenotypic and genotypic data was obtained from all participants in accordance with Institution Review Board-approved protocols for each center. To examine the presence of the variant in the control population, a group composed of 400 individuals was used. Controls were Spanish individuals free cancer recruited between 1999 and 2005 through the following sources: 287 (72\%) from the Menopause Research Centre at the Instituto Palacios, Madrid, and 113 (28\%) from the National Blood Transfusion Centre, Madrid. Informed consent was obtained from all participants.

\section{DNA extraction and sequencing}

DNA extraction was carried out by using QIAamp DNA Blood Kit (Qiagen). Germline DNA sequences of CDKN1B, representing the coding regions and intronexon boundaries, were amplified by PCR. PCR was performed with AmpliTaq Gold with GeneAmp (Applied Biosystems, Foster City, CA, USA). The conditions were: $10 \mathrm{~min}$ at $94{ }^{\circ} \mathrm{C}$ for Taq Gold activation, 35 cycles at $94{ }^{\circ} \mathrm{C}$ for $30 \mathrm{~s}$, annealing at $60{ }^{\circ} \mathrm{C}$ (exon 1) or $55^{\circ} \mathrm{C}$ (exon 2) for $30 \mathrm{~s}$, extension at $72^{\circ} \mathrm{C}$ for $60 \mathrm{~s}$, and then for $5 \mathrm{~min}$ at $72{ }^{\circ} \mathrm{C}$.

Table 1 Clinical characteristics of index cases. The age of onset indicates the age at diagnosis of the first tumor. The clinical presentation refers to the clinical signs developed by the patients; the age at diagnosis of each tumor is indicated in brackets.

\begin{tabular}{llclll}
\hline $\begin{array}{l}\text { Patient } \\
\text { ID }\end{array}$ & Gender & $\begin{array}{c}\text { Onset } \\
\text { (years) }\end{array}$ & Clinical presentation & $\begin{array}{l}\text { MEN1 gross } \\
\text { deletion }^{\text {a }}\end{array}$ & Family \\
\hline 1 & Female & 55 & HPT (adenoma) (67), pituitary adenoma (GH) (55) & NA & No \\
2 & Female & 56 & HPT (56), pituitary adenoma (GH) (56) & NA & No \\
3 & Female & 68 & HPT (68) , pituitary adenoma (non-secretory) (68) & Negative & No \\
4 & Male & 62 & HPT (62), pituitary macroadenoma (ACTH) (65) & Negative & No \\
5 & Female & 44 & HPT (53), pituitary adenoma (GH) (44) & Negative & No \\
6 & Female & 56 & HPT (63), pituitary adenoma (non-secretory) (56) & NA & No \\
7 & Female & 69 & Gastric carcinoid tumor (69), HPT (74) & Negative & No \\
8 & Female & 65 & Insulinoma (65), adrenal adenoma (65) & Negative & No \\
9 & Female & 62 & Insulinoma (62), adrenal adenoma (67) & Negative & No \\
10 & Female & 62 & Insulinoma (62), adrenal adenoma (67) & Negative & No \\
11 & Male & 73 & HPT (73), macroprolactinoma (73) & Negative & No \\
12 & Female & 78 & HPT insulinoma carcinoid tumor (lung) goiter & Negative & Yes \\
13 & Female & 59 & HPT (63), pituitary adenoma (GH) (59) & No \\
14 & Female & - & HPT pituitary adenoma (GH), renal carcinoma & Negative & \\
15 & Female & 54 & Carcinoid tumor (bronchial) (54), collagenoma (55), & & \\
& & & adrenal adenoma (55) & &
\end{tabular}

PRL, prolactin; NA, not assessed.

${ }^{a}$ MEN1 gross deletion was assessed by multiplex ligation-dependent probe amplification (MLPA), according to the manufacturer's instructions (MRC-Holland, Amsterdam, Holland)

${ }^{\mathrm{b}}$ Multiglandular.

${ }^{\mathrm{C}}$ Patient with familial antecedents (son diagnosed with HPT $1^{\circ}$ at the age of 32 years). 
Part of exon 1 (605 bp) was amplified with primers 5'-GGCGCTTTGTTTTGTTCGG-3' and 5'-CCCTCCAGCAGGCAAAGCG-3'. Exon 2 (333 bp) was amplified with primers $5^{\prime}$-CCTTAAAAGCCACTGGGGATG-3' and 5'-CGTGAGGTCTGAAGGCCCC-3'. PCR products were purified using QIAquick PCR Purification Kit (Qiagen) and sequenced in one or both directions. Sequencing results were both machine-read and manually read by two of the authors (D Malanga and S De Gisi) independently.

\section{Constructs}

We cloned the minimal regulatory region of the CDKN1B gene that has been shown to be able to efficiently drive transcription of a downstream reporter gene $(29,30,31)$. DNA fragments from the $5^{\prime}$ region of the CDKN1B gene between nucleotides -575 and -1 were generated through PCR using genomic DNA of a donor sample with forward $5^{\prime}$-GGTACCGGTACCCCACCTTAAGGCCGCGCTCG- $3^{\prime}$ and reverse 5'-AAGCTTA AGCTTCTTTCTCCCGGGTCTGCACG-3' primers containing KpnI and HindIII sites respectively. PCR products were cloned into the pGL3-basic promoterless plasmid (Promega) to generate pGL3-5'-UTR-WT and to drive expression of the downstream luciferase gene. After cloning, the construct was subject to site mutagenesis using the site-directed mutagenesis system kit (Invitrogen) to generate the pGL3-5' -UTR-MUT, carrying the c.-32_-29del using the following primers: forward 5'-GTTTTTTTGAGAGTGCGAGGCGGTCGTGCAG-3' and reverse 5'-CTGCACGACCGCCTCGCACTCTCAAAAAAAC- $3^{\prime}$. Plasmids generated for each genotype were confirmed by direct sequencing. To generate pGL3-promoter-5' -UTR-WT and pGL3promoter- $5^{\prime}$-UTR-MUT, we amplified from the previous corresponding constructs the CDKN1B 5'-UTR with forward 5'-AAGCTTAAGCTTCCCCACCTTAAGGCCGCGCTCG-3' and reverse 5'-CCATGGCCATGGTGGCTTTACCAACAGTACCGGAAT- ${ }^{\prime}$ primers containing HindIII and NcoI sites respectively. The PCR products were inserted in the HindIII and NcoI restriction sites of pGL3 promoter (Promega). For in vitro coupled transcription/translation experiments, the $2 \mathrm{~kb} \mathrm{KpnI/}$ XbaI restriction fragments from pGL3-5'-UTR-WT and pGL3-5'-UTR-MUT were cloned in pcDNA3 (Invitrogen) to obtain the constructs pcDNA3-5'-UTR-WTLuc and pcDNA3-5'-UTR-MUTLuc respectively.

\section{Cell culture and transfection}

HeLa cells (American Type Culture Collection) were incubated at $37^{\circ} \mathrm{C}$ in a humidified $5 \% \mathrm{CO}_{2}$ atmosphere in DMEM - high glucose medium (Sigma-Aldrich) supplemented with $100 \mathrm{U} / \mathrm{ml}$ penicillin, $0.1 \mathrm{mg} / \mathrm{ml}$ streptomycin, and 10\% fetal bovine serum. Transfections were performed with Trans lT-LT1 Transfection Reagent (Mirus Bio LLC, Madison, WI, USA) following the manufacturer's protocol.

\section{In vitro transcription}

In vitro transcription (IVT) reactions were performed by the Riboprobe in vitro transcription systems (Promega). The constructs were linearized with StuII and subjected to the reaction following manufacturer's recommendations. The IVT RNAs were separated using 1.5\% denaturing agarose gel electrophoresis and analyzed by densitometry.

\section{Luciferase reporter gene assays}

For Luciferase activity assays, cells were transfected with $1 \mu \mathrm{g}$ of the promoter/luciferase reporter plasmids, and with $100 \mathrm{ng}$ pRL Renilla as control vector (Promega) to correct for differences in transfection efficiency. Cells were collected 24 and $48 \mathrm{~h}$ after transfection by centrifugation, washed twice with PBS, and lysed with $100 \mu \mathrm{l}$ cell lysis reagent (DualLuciferase Reporter Assay System, Promega). Cell lysates were dispensed into luminometer plates, followed by sequential auto-injection of the Luciferase Assay Reagent for firefly luciferase activity measurement and Stop\&Glo Reagent for Renilla luciferase activity measurement (Dual-Luciferase Reporter Assay System, Promega). Basal luciferase activity was examined in cells transfected with an empty vector (pGL3 Basic or Promoter Vector). Three independent transfections were performed for each construct in triplicate.

\section{IVT/transIation}

Coupled transcription/translation reactions were performed by the TNT Coupled Reticulocyte Lysate (Promega) standard rabbit reticulocyte systems. The constructs were linearized with PvuI and subjected to $90 \mathrm{~min}$ reaction following manufacturer's recommendations. After completion of the reaction, $5 \mu \mathrm{l}$ of the reaction mixture was added to $100 \mu \mathrm{l}$ Luciferase Assay Reagent for firefly luciferase activity measurement.

\section{cDNA synthesis and real-time quantitative RT-PCR}

We obtained cDNA from RNA isolated from HeLa cells or from peripheral blood leukocytes of the patient genotyped in the study and from five healthy controls. One microgram of total RNA was reverse-transcribed using Superscript II Reverse Transcriptase (Invitrogen) and an oligo dT18 primer, according to the manufacturer's instructions. The amount of CDKN1B mRNA was quantified by real-time PCR with the Sequence Detection System 7900HT (Applied Biosystems), using primers p27QF (5'-CCCTAGAGGGCAAGTACGAGT-3') and p27QR (5'-AGTAGAACTCGGGCAAGCTG-3'). For the evaluation of luciferase and Renilla mRNAs, 
we used the following primers respectively: luciferase forward (5'-ATCCATCTTGCTCCAACACC- $\left.3^{\prime}\right)$ and reverse (5'-TTTTCCGTCATCGTCTTTCC- $\left.3^{\prime}\right)$ and Renilla forward (5'-ACAAGTACCTCACCGCTTGG-3') and reverse (5'-GACACTCTCAGCATGGACGA-3'). The amplification conditions were: an initial step at $95^{\circ} \mathrm{C}$ for $10 \mathrm{~min}$, followed by 40 cycles of $15 \mathrm{~s}$ at $95^{\circ} \mathrm{C}$ and $1 \mathrm{~min}$ at $60^{\circ} \mathrm{C}$. Normalization was carried out with the internal standard GAPDH (forward primer, $5^{\prime}$-AACGGATTTGGTCGTATTGGGC-3' and reverse primer, 5'-TCGCTCCTGGAAGATGGTGATG-3'). All reactions were in the initial exponential amplification phase and the cycle at which each sample crossed the threshold $\left(C_{\mathrm{t}}\right)$ was recorded for CDKN1B and GAPDH. The $\Delta \Delta C_{t}$ method was used for the calculation of the different amounts of mRNA (32). Negative controls were included in all PCR reactions and assays were carried out in triplicate.

Student's t-test was used for statistical analysis.

\section{Results \\ CDKN1B sequencing in index cases}

There were 15 index cases negative for MEN1 germline mutations and classified as MEN-like, that were considered as candidates for the p27 mutational screening. Among the 15 index cases, it was also possible to discard the presence of MEN1 large deletion/duplication by multiplex ligation-dependent probe amplification in 11 patients with high-quality DNA (Table 1). Among them, nine developed hyperparathyroidism (HPT) and pituitary adenoma (five GH-secreting, one ACTH-secreting, one prolactinoma, and two non-secreting), two had HPT and gastric carcinoid tumor, or insulinoma and bronchial carcinoid tumor, three were diagnosed with insulinoma and adrenal adenoma, and one patient was affected by a bronchial carcinoid tumor, a collagenoma and adrenal adenoma (see Table 1).

Among these 15 MEN-like probands, we detected the presence of a heterozygous GAGA deletion at $5^{\prime}$-UTR, c.-32_-29del in the patient ID7, a 69-year-old Spanish female affected by gastric carcinoid tumor and HPT (see Fig. 1A and B). Patients' clinical data are shown in Table 1. Sequence comparison of the 5'-UTR among human, mouse, and rat showed that these four nucleotides were highly conserved among all species analyzed, suggesting functional relevance of the sequence (Fig. 1C).

\section{Functional effects of the $5^{\prime}$-UTR $-32 /-29$ GAGA deletion}

To functionally characterize the deletion detected in the patient ID7, we cloned the PCR fragment amplified from genomic DNA, corresponding to the -575 to -1
A

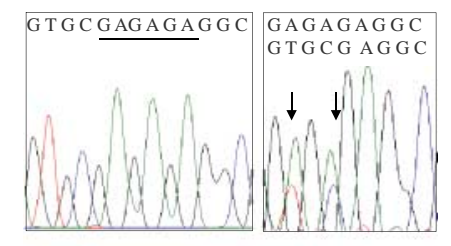

B

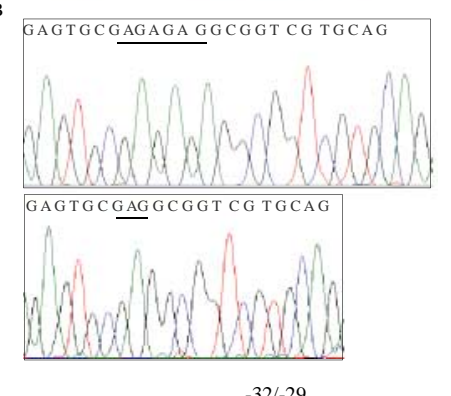

WT TTTTTGAGAGTGCGAGAGAGGCGGTCGTGCAGACCCGGGAGAAAGATG MUTTTTTTGAGAGTGC ----- GAGGCGGTCGTGCAGACCCGGGAGAAAGATG

$\mathrm{C}$

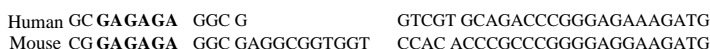
Rat CG GAGAGA GGC GAGGCGGTGGT CCAC ACCCGCCCGAGGAGGAAGATG

Figure 1 Germline mutation in the $C D K N 1 B$ gene in a MEN1-like patient. (A) Left panel shows the genomic wild-type sequence of the region spanning nucleotides $-32 /-29$ (underlined) in the CDKN1B gene of a healthy control; right panel shows the genomic sequence of patient ID7 with the presence of a $4 \mathrm{bp}$ deletion encompassing nucleotides -32/-29 (arrows). (B) Sequences of the PCR fragments cloned from genomic DNA of the patient ID7. The upper panel shows the WT sequence (-32/-27 GAGA nucleotide underlined); the lower panel shows the sequence of the mutant fragment with deleted GAGA at nucleotides -32/-29 (MUT) (dashed line).

(C) Homology between the different $5^{\prime}$-UTR sequences of $C D K N 1 B$ orthologs in the mouse, rat, and human. Full colour version of this figure available via http://dx.doi.org/10.1530/EJE-11-0929.

nucleotides, into the PCR-Topo Cloning Vector. The sequencing of the cloned PCR product confirmed the presence of a heterozygous GAGA deletion as shown in Fig. 1B.

Transcription from CDKN1B is initiated predominantly from a single site which is conserved in the human and mouse genes $(29,30,31)$. Initiation at this site produces a $5^{\prime}$-UTR of 472 nucleotides in the human CDKN1B mRNA and 502 nucleotides in the mouse Cdkn1B mRNA. In addition, several minor transcription start sites were identified for both the mouse and human genes $(29,30,31)$. In addition to the capability to drive transcription of a downstream reporter gene, the $5^{\prime}$-UTR region of human CDKN1B contains a U-rich element that is involved in regulating CDKN1B mRNA stability and/or translation efficacy (33). In fact, several mRNA-binding proteins were found to interact with the CDKN1B 5'-UTR and to regulate its expression (34).

For this reason, to investigate whether the deleted $5^{\prime}$-UTR sequence detected in the patient ID7 affected the expression of CDKN1B mRNA and/or protein, we decided to clone the minimal regulatory region of the 
CDKN1B gene that has been shown to efficiently drive transcription of a downstream reporter gene $(30,31$, 35,36 ) and measure the effects on transcription exerted by the mutant allele. For this purpose, the $575 \mathrm{bp}$ sequence in the CDKN1B 5'-UTR was PCR amplified from wild-type or mutant genomic DNAs and inserted upstream of the firefly luciferase reporter gene in the promoterless pGL3 vector, generating wild-type (5'-UTR-WT) and deleted (5'-UTR-MUT) constructs (Fig. 2A). These constructs were transfected into HeLa cells and luciferase activity was determined $48 \mathrm{~h}$ after transfection. As shown in Fig. 2B, cells transfected with luciferase cDNA under the control of the $5^{\prime}$-UTR-MUT showed a significant reduction (almost $40 \%$; $P$ value $<0.0024)$ in the luciferase activity, compared with cells transfected with the 5'-UTR-WT construct. Analysis by real-time quantitative RT-PCR indicated that the steady-state levels of luciferase mRNA produced by the 5'-UTR-MUT construct were less abundant $(\sim 32 \%)$ than those produced by $5^{\prime}$-UTR-WT (Fig. 2C). Similar results were obtained when transfected cells were deprived of serum, as shown in Fig. 2D.

The 5'-UTR of both human and mouse CDKN1B genes have been shown to contain an internal ribosome entry site (IRES) $(37,38)$. The ribosome entry window for the IRES-dependent translation is located between nucleotides -50 and -36 upstream of the p27 translation start codon (for the sake of clarity, we set the A nucleotide of the ATG translation start codon as +1 ), within a U-rich region that forms a large singlestranded loop $(33,38,39)$. We performed a secondary structure prediction of the $5^{\prime}$-UTR-WT $(-575 /-1)$ sequence using a web-based application from www.tbi. univie.ac.at/ ivo/RNA/ (40, 41). As shown in Fig. 3, the 575 nucleotides of $5^{\prime}$-UTR in the wild-type CDKN1B (5'-UTR-WT) contain a secondary stem and loop structure that includes the element $-32 /-29$ GAGAGA. This loop contains a U-rich region that has previously been shown to interact with mRNA-binding proteins and to modulate ribosome recruitment $(19,38$, 39). The ribosome entry window for IRES-initiated translation is between nucleotides 36 and 50 (indicated by stars in Fig. 3) (38). Conversely, the secondary structure prediction of the 575-nucleotide-long $5^{\prime}$-UTR of the mutant patient ID7 (5'-UTR-MUT) shows a different secondary structure, with the destruction of the predicted stem and loop. This observation suggested that the $-32 /-29$ GAGA may impair the translation efficacy of mutant CDKN1B gene.

We further investigated whether the sequence comprising the $-32 /-29$ GAGA element is important for the control of transcription and/or translation efficiency of CDKN1B mRNA. First, we performed an in vitro coupled transcription-translation assay. With this aim, we introduced the CDKN1B 5'-UTR-WT or the $5^{\prime}$-UTR-MUT sequences upstream of the AUG initiation codon of luciferase cDNA into the pcDNA3 vector under the transcriptional control of the $\mathrm{T} 7$ promoter, as shown
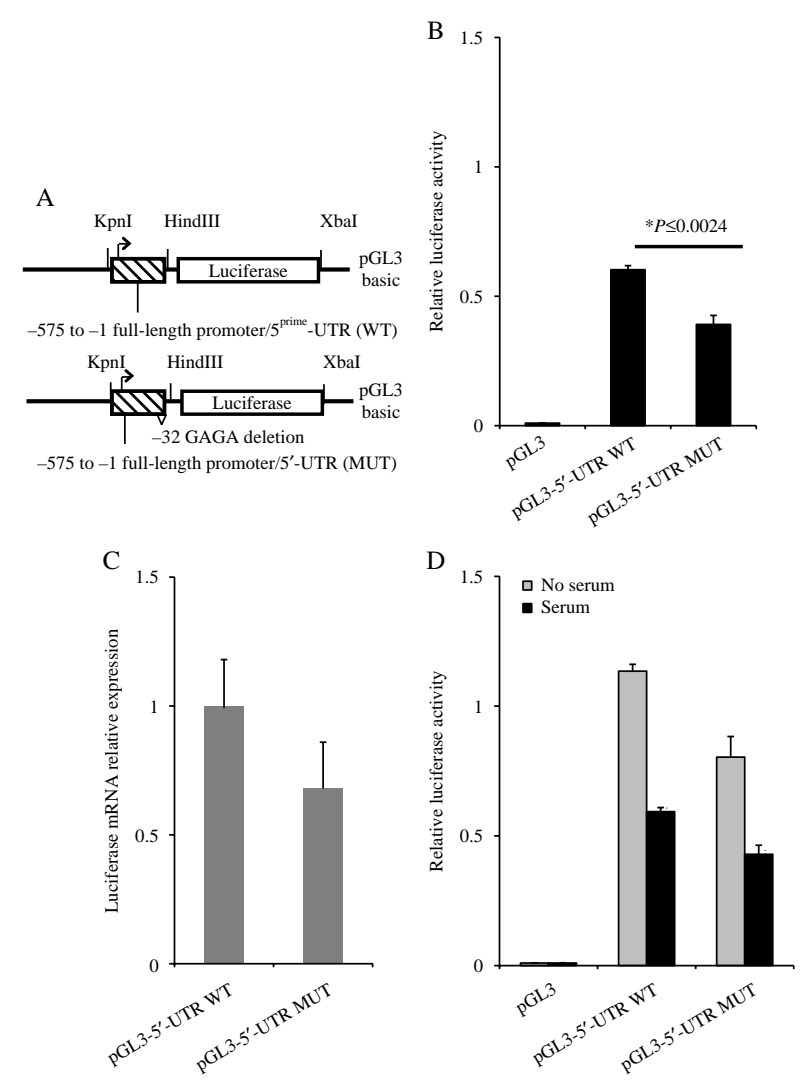

Figure 2 Transcription rate mediated by the wild-type or mutant CDKN1B promoter/5'-UTR region. (A) Schematic diagram of $\mathrm{pGL3}$ promoterless constructs carrying wild-type sequence ( $5^{\prime}$-UTR-WT) or the $-32 /-29$ GAGA deletion (5'-UTR-MUT). (B) Luciferase assay. HeLa cells were transfected with constructs encoding luciferase under the control of CDKN1B 5'-UTR-WT or 5'-UTRMUT respectively. After $48 \mathrm{~h}$ of transfection, the cells were harvested and luciferase activity was determined and normalized to the co-transfected Renilla. Luciferase activity was expressed as relative values to those generated by the empty vector pGL3 as mean of three replicates. ${ }^{\star} P<0.0024$. (C) Q-RT-PCR analysis of luciferase mRNA expression mediated by the wild-type or mutant $C D K N 1 B 5^{\prime}$-UTR region. HeLa cells were transfected with constructs ( $p$ GL3 promoterless) encoding luciferase under the control of CDKN1B 5'-UTR-WT or 5'-UTR-MUT. After $48 \mathrm{~h}$ of transfection, the cells were harvested and luciferase mRNA was quantified and normalized to the co-transfected Renilla in real-time PCR. Values were expressed relative to those generated by the pGL3-5'-UTR-WT as mean of three replicates. (D) Luciferase assay. PGL3 promoterless constructs encoding luciferase under the control of CDKN1B 5'-UTR-WT or 5'-UTR-MUT were transfected into HeLa cells in the presence or absence of serum. After $48 \mathrm{~h}$, the cells were harvested and luciferase activity was determined and normalized to the co-transfected Renilla as above. Luciferase activity was expressed as relative values to those generated by the empty vector pGL3 as mean of three replicates.

in Fig. 4A (pcDNA3-5'-UTR-WTLuc and pcDNA3-5'UTR-MUTLuc respectively). Subsequently, both pcDNA3-5'-UTR-WTLuc and the pcDNA3-5'-UTRMUT Luc constructs were subjected to in vitro coupled transcription-translation in a system of rabbit reticulocytes. After completing the reaction, the activity of the newly synthesized, functionally active luciferase was 
A 5'-UTR WT

MFE $-210.14 \mathrm{kcal} / \mathrm{mol}$ B

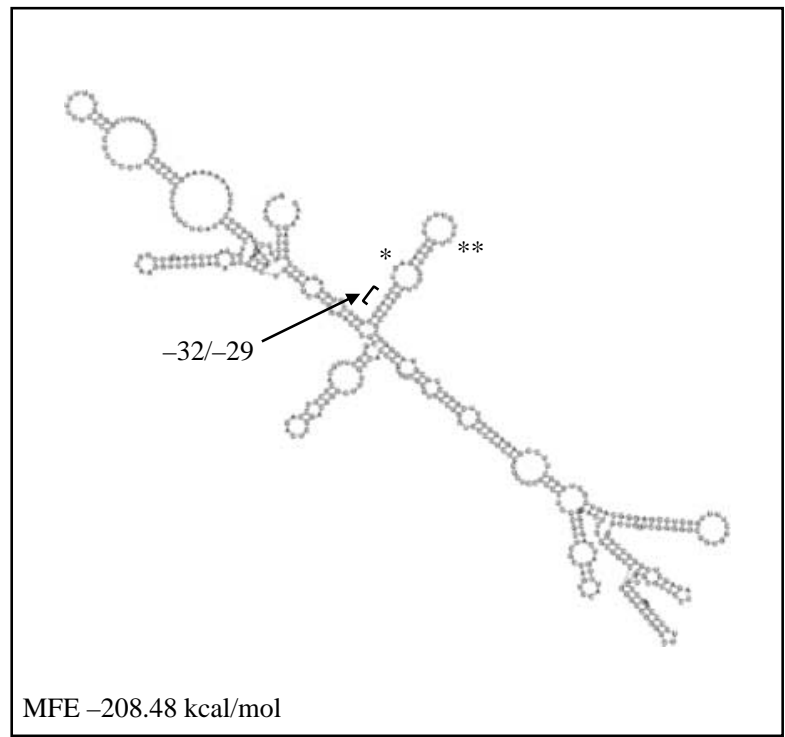

Figure 3 (A) Secondary structure prediction for the 575 bp $5^{\prime}$-UTRWT region of $C D K N 1 B$ gene. (B) Secondary structure prediction for the 575 bp $5^{\prime}$-UTR-MUT region of $C D K N 1 B$ gene. Deleted regions are indicated by the arrow and brackets. The minimum free energy (MFE) for each structure is indicated at the bottom. See text for details.

measured with a luminometer. As shown in Fig. 4B, it is notable that there was a significant reduction (of $\sim 40 \%$; $P$ value $=0.0032$ ) in the luciferase activity when the CDKN1B 5'-UTR-MUT was placed upstream of the luciferase coding region compared with the same construct containing 5'-UTR-WT. A parallel analysis by quantitative real-time RT-PCR of the luciferase mRNA produced by the pcDNA3-5'-UTR-WTLuc and the pcDNA3-5'-UTR-MUTLuc constructs, respectively, demonstrated that the mRNA abundance transcribed by the $5^{\prime}$-UTR-MUT construct was $\sim 70 \%$ of the mRNA abundance transcribed by the $5^{\prime}$-UTR-WT construct, with a reduction of about 30\% (Fig. 4C).

To measure the contribution of the $5^{\prime}$-UTR sequence to the transcription and/or translation of CDKN1B mRNA in the living cells, we inserted the full-length 5'-UTR-WT and the deleted 5'-UTR-MUT sequences upstream of the luciferase reporter gene in the pGL3promoter plasmid, which contains the SV40 promoter element (Fig. 5A). These constructs were then transfected into HeLa cells and the luciferase activity or luciferase mRNA levels were measured after $48 \mathrm{~h}$ respectively. As shown in Fig. 5B, after normalizing luciferase activity for the internal Renilla control, the average of luciferase activity shown by the pGL3promoter-5'-UTR-MUT plasmid was consistently lower ( $\sim 40 \%$ ) compared with that shown by pGL3-promoter$5^{\prime}$-UTR-WT plasmid at the same time point $(P$ value $<0.0018)$. Conversely, the analysis of luciferase mRNA levels by quantitative real-time RT-PCR demonstrated that the mRNA abundance transcribed by the $5^{\prime}$-UTRMUT construct was reduced by only 30\% compared with that transcribed by the $5^{\prime}$-UTR-WT construct (Fig. 4C).

Altogether, these results suggested that the deleted $-32 /-29$ GAGA region exerted a critical control on transcription and/or translation of CDKN1B mRNA. In particular, the finding that compared with $5^{\prime}$-UTR-WT, the reduction in the activity of the luciferase driven by

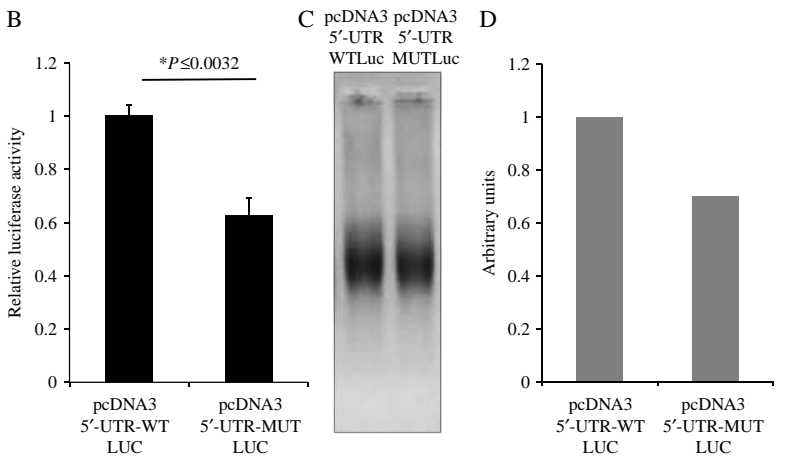

Figure 4 Coupled transcription/translation analysis of wild-type or mutant $C D K N 1 B$ promoter $/ 5^{\prime}-$ UTR region. (A) Schematic diagram of pcDNA3 Luc constructs carrying wild-type sequence (5'-UTRWT) or the -32/-29 GAGA deletion (5'-UTR-MUT). (B) Luciferase assay. The level of functional luciferase expression was measured by a Luminometer as a mean of three replicates and expressed relative to pCDNA3-5'-UTR-WTLuc. ${ }^{*} P<0.0032$. (C) In vitro transcription of $C D K N 1 B 5^{\prime}$-UTR luciferase mRNA. The luciferase RNA transcripts were generated by in vitro transcription using $1 \mu \mathrm{g}$ Stul linearized plasmids and T7 RNA polymerase. Right panel, densitometry data obtained from IVT RNA bands by ImageJ Software (free software provided by NIH, MD, USA). 


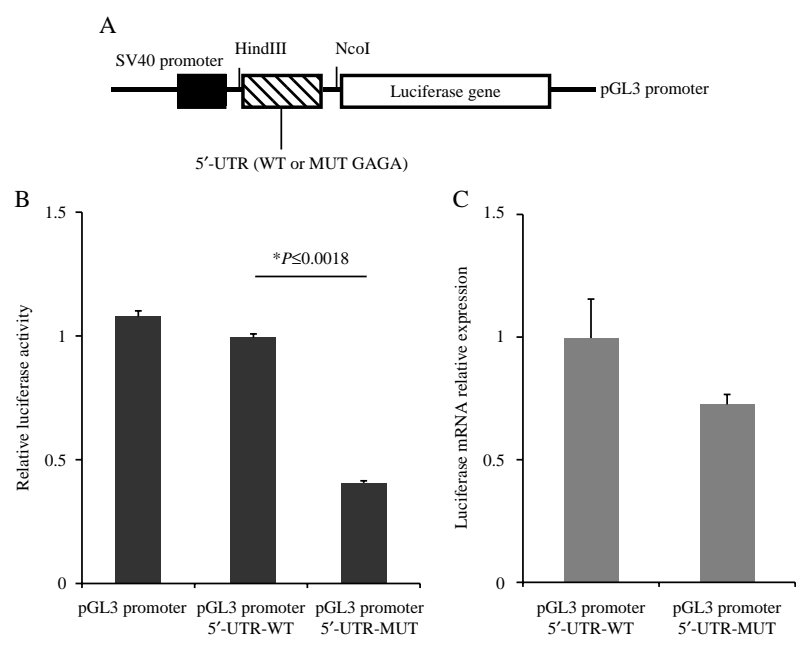

Figure 5 Transcription and translation rates mediated by the wildtype or mutant $C D K N 1 B$ promoter $/ 5^{\prime}$-UTR region. (A) Schematic diagram of pGL3 promoter constructs carrying wild-type sequence (5'-UTR-WT) or the $-32 /-29$ GAGA deletion (5'-UTR-MUT). (B) Luciferase assay. HeLa cells were transfected with pGL3promoter-5'-UTR-WT or pGL3-promoter-5'-UTR-MUT. After $48 \mathrm{~h}$ of transfection, the cells were harvested and luciferase activity was determined and normalized to the co-transfected Renilla. Luciferase activity was expressed as relative values to those generated by the empty vector pGL3 as mean of three replicates. ${ }^{*} P \leq 0.0018$.

(C) Q-RT-PCR analysis of luciferase mRNA expression mediated by the wild-type or mutant promoter $/ 5^{\prime}$-UTR region. HeLa cells were transfected with pGL3-promoter-5'-UTR-WT or pGL3-promoter-5' UTR-MUT constructs. After $48 \mathrm{~h}$ of transfection, the cells were harvested and luciferase mRNA was determined and normalized to the co-transfected Renilla in real-time PCR. Values were expressed relative to those generated by the pGL3 promoter $5^{\prime}-$ UTR-WT as mean of three replicates.

5'-UTR-MUT was slightly more consistent than the reduction in mRNA levels, suggesting that the $-32 /$ -29 GAGA deletion in the $5^{\prime}$-UTR region of CDKN1B may impair both transcription and translation.

\section{Expression of CDKN1B mRNA in peripheral blood leukocytes of patient ID7}

All these observations prompted us to evaluate whether the presence of the GAGA deletion affects the expression level of CDKN1B mRNA in the patient ID7 in vivo. With this aim, we analyzed CDKN1B mRNA expression in the mRNA extracted from the peripheral blood leukocytes of patient ID02S514 and from several healthy donors. As shown in Fig. 6, quantitative RT-PCR revealed a statistically significant difference between the average CDKN1B mRNA expression of healthy donors $(n=5)$ and the level of CDKN1B mRNA in the patient ID7. The GAGA deletion resulted in a threefold reduction in mRNA levels compared with healthy controls $(P$ value $=0.024)$, indicating that the mutant $C D K N 1 B$ genotype was associated with decreased expression of CDKN1B mRNA. Since protein samples were unavailable from this patient, we could not determine the effects of the mutation on the protein level, both in the blood and tumor of patient ID7.

\section{Discussion}

Recently, a syndrome termed MENX with features overlapping MEN1 and MEN2 in the rat was attributed to a homozygous inactivating mutation of the $\mathrm{Cdk}$ inhibitor CDKN1B gene. This finding has prompted us to search CDKN1B mutations in MEN1- and RETnegative patients showing a MEN-like phenotype in the human. To date, six germline mutations have been identified leading to the definition of a new type of MEN-like syndrome in the human, named MEN4, though the phenotypic features are still undefined due to the small number of patients reported $(1,2,3,4,5)$. Most CDKN1B mutations reported so far associated with MEN4 syndrome are inactivating mutations that lead to prematurely truncated protein (TGG $>$ TAG at codon 76 (p.W76X)) (4) or to a premature stop at codon 69 caused by a 19 bp duplication (2), to a protein predicted to be 60 amino acids longer due to a change in the stop codon (TAA to CAA; stop to Q) (3). In this study, we have identified a novel germline mutation in the CDKN1B gene in a proband affected by gastric carcinoid tumor and HPT, that was negative for mutations in MEN1 and RET, being classified as a MEN-like syndrome. We provided evidence that the observed GAGA deletion encompassing nucleotides $-32 /-29$ of

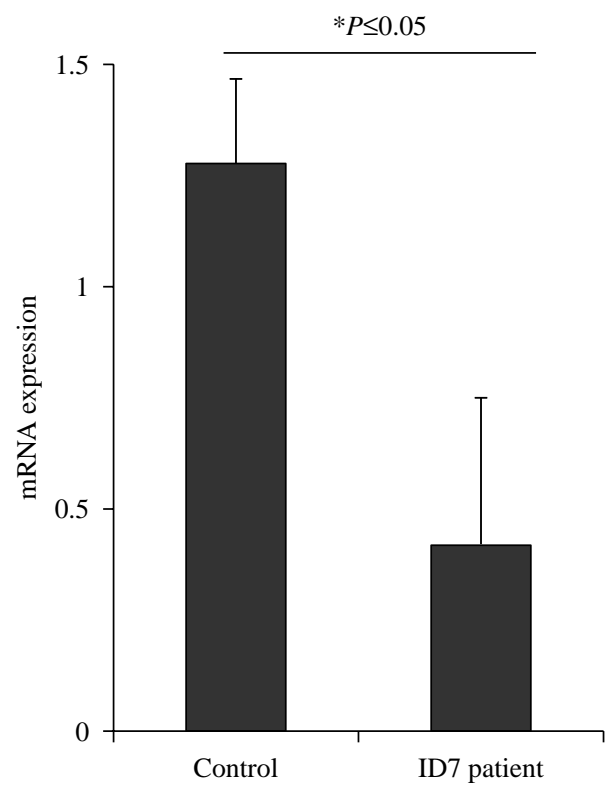

Figure $6 \mathrm{Q}-\mathrm{RT}$-PCR analysis of $C D K N 1 B$ expression in the MEN1like patient and healthy controls. The Q-RT-PCR was performed on mRNA extracted from peripheral blood leukocytes. These results are representative of two independent experiments on total RNA. ${ }^{*} P \leq 0.05$. 
5'-UTR significantly impairs transcription and, possibly, translation of CDKN1B mRNA. It is worthy of mention that a previous study identified a mutation at the -7 position in the Kozak sequence (G to $\mathrm{C}$ ) of CDKN1B in a patient with a parathyroid tumor and adrenal masses, suggesting that germline mutations that lead to impairment of transcription and/or translation of CDKN1B may be common in MEN1-like syndrome (3).

Transcription from CDKN1B is initiated predominantly from a single site that produces a $5^{\prime}$-UTR of 472 nucleotides in the human CDKN1B mRNA $(29,30,31)$. Our results indicate that the GAGA deletion significantly impairs transcription in vitro and in vivo, since: i) studies of in vitro coupled transcription/translation of the CDKN1B 5'-UTR $(-575 /-1)$ carrying the c.-32_29del upstream a luciferase reporter gene was transcribed with significant minor efficiency compared with a construct carrying the wild-type CDKN1B 5'UTR ( $-575 /-1)$; ii) transient transfection experiments in HeLa cells showed that the GAGA deletion encompassing $-32 /-29$ nucleotides in the $5^{\prime}$-UTR $(-575 /-1)$ of CDKN1B significantly impairs the transcription of a downstream luciferase reporter gene; and finally iii) the $-32 /-29$ deletion mutant associates with a significant reduction in the amount of CDKN1B mRNA in the peripheral blood leukocytes of the patient.

In addition to the capability to drive transcription of a downstream reporter gene, the $5^{\prime}$-UTR region of human CDKN1B contains a U-rich element that is involved in regulating $C D K N 1 B$ mRNA stability and/or translation efficacy (33). Computed analysis of CDKN1B 5'-UTR suggested that the c.-32-29del mutant destroys such secondary structure, thus impairing ribosome entry. Although not definitive, our data also indicate that the $-32 /-29$ deletion may also impair the translation of CDKN1B mRNA, since we consistently observed that the reduction in the activity of luciferase driven by $5^{\prime}$-UTR-MUT was slightly more consistent than the reduction in mRNA levels.

This work also provides evidence that haploinsufficient expression of CDKN1B might be implicated in tumor predisposition in MEN-like patients. In fact, although we were not able to assess the level of p27 protein, we found that the heterozygous $-32 /-29$ deletion mutant was associated with a significant reduction in the amount of CDKN1B mRNA in the peripheral blood leukocytes of the patient considered for this study. Accordingly, several lines of evidence indicate that even small changes in the amount of $\mathrm{p} 27$ protein can have dramatic phenotypic consequences. A drastic reduction of CDKN1B expression has been observed in almost $50 \%$ of all human cancers, usually correlating with histological aggressiveness and poor outcome (6, $7,8,9,10)$. The analysis of animal models has demonstrated that the lack of p27 is able to promote tumor formation. These consequences can be attributed to the role of p27 as a mediator of anti-mitogenic signals. In the absence of p27, cells exposed to signals that induce growth arrest fail to properly withdraw from the cell cycle, undergoing more mitotic divisions and neoplastic transformation. It is noteworthy that several genes in this cell-cycle regulating pathway have been implicated in endocrine tumors in man and mouse. First, both MEN1 and RET apparently regulate the expression of $C D K N 1 B$ and $p 18$, suggesting that these Cdk inhibitors might serve as negative growth regulators in MEN-like tumors; $C d k n 1 b$-null mice develop intermediate lobe pituitary adenomas (frequency $100 \%)(25,26,27)$; mice with various combinations of knockout of CDKN1B and $p 18$ show tumors of pituitary, thyroid C-cells, parathyroids, adrenal medulla, endocrine pancreas, testis, and duodenum, with symptoms that resemble MEN1 and MEN2 (42, 43); and finally, MENX rats that display extremely reduced/absent p27 expression in their tissues develop multiple endocrine tumors (1). In conclusion, these results extend previous studies on MEN4 and indicate that CDKN1B germline mutations may predispose to a human MEN4 condition, although they are fairly uncommon, and add novel evidence that alteration in the transcription/translation rate of CDKN1B mRNA might be the mechanism implicated in tumor susceptibility.

\section{Declaration of interest}

The authors declare that there is no conflict of interest that could be perceived as prejudicing the impartiality of the research reported.

\section{Funding}

Funding agency: MIUR (PRIN, 20087FSFFP_001).

\section{Acknowledgements}

This study was supported by a grant from Ministero dell'Università e della Ricerca (PRIN, 20087FSFFP_001) to G Viglietto. C De Marco was supported by a fellowship from 'Fondazione per il Sud' at the University of Salerno.

\section{References}

1 Pellegata NS, Quintanilla-Martinez L, Siggelkow H, Samson E, Bink K, Höfler H, Fend F, Graw J \& Atkinson MJ. Germ-line mutations in p27Kip1 cause a multiple endocrine neoplasia syndrome in rats and humans. PNAS $2006 \mathbf{1 7} 15558-15563$. (doi:10.1073/pnas.0603877103)

2 Georgitsi M, Raitila A, Karhu A, van der Luijt RB, Aalfs CM, Sane T, Vierimaa O, Mäkinen MJ, Tuppurainen K, Paschke R, Gimm O, Koch CA, Gündogdu S, Lucassen A, Tischkowitz M, Izatt L, Aylwin S, Bano G, Hodgson S, De Menis E, Launonen V, Vahteristo P \& Aaltonen LA. Germline cdkn1b/p27Kip1 mutation in multiple endocrine neoplasia. Journal of Clinical Endocrinology and Metabolism 200792 3321-3325. (doi:10.1210/jc.20062843)

3 Agarwal SK, Mateo CM \& Marx SJ. Rare germline mutations in cyclin-dependent kinase inhibitor genes in multiple endocrine 
neoplasia type 1 and related states. Journal of Clinical Endocrinology and Metabolism 200994 1826-1834. (doi:10.1210/jc.20082083)

4 Molatore S, Marinoni I, Lee M, Pulz E, Ambrosio MR, Uberti EC, Zatelli MC \& Pellegata NS. A novel germline cdkn1b mutation causing multiple endocrine tumors: clinical, genetic and functional characterization. Human Mutation 201031 E1825-E1835. (doi:10. 1002/humu.21354)

5 Marinoni I \& Pellegata NS. p27kip1: a new multiple endocrine neoplasia gene? Neuroendocrinology 201193 19-28. (doi:10. $1159 / 000320366)$

6 Slingerland J \& Pagano M. Regulation of the cdk inhibitor p27 and its deregulation in cancer. Journal of Cellular Physiology 2000 183 10-17. (doi:10.1002/(SICI)1097-4652(200004)183:1 $<10:$ :AID-JCP2 $>3.0$. CO 2 -I)

7 Chu IM, Hengst L \& Slingerland JM. The Cdk inhibitor p27 in human cancer: prognostic potential and relevance to anticancer therapy. Nature Reviews. Cancer 20088 253-267. (doi:10.1038/ nrc2347)

8 Mori M, Mimori K, Shiraishi T, Tanaka S, Ueo H, Sugimachi K \& Akiyoshi T. p27 expression and gastric carcinoma. Nature Medicine 19973 593-597. (doi:10.1038/nm0697-593)

9 Yasui W, Kudo Y, Semba S, Yokozaki H \& Tahara E. Reduced expression of cyclin-dependent kinase inhibitor p27Kip1 is associated with advanced stage and invasiveness of gastric carcinomas. Japanese Journal of Cancer Research 199788 625-629. (doi:10.1111/j.1349-7006.1997.tb00428.x)

10 Kim WH, Ghil KC, Lee JH, Yeo SH, Chun YJ, Choi KH, Kim DK \& Kim MY. Involvement of p27(kip1) in ceramide-mediated apoptosis in HL-60 cells. Cancer Letters 20003 39-48. (doi:10. 1016/S0304-3835(99)00402-4)

11 Singh SP, Lipman J, Goldman H, Ellis FH Jr, Aizenman L, Cangi MG, Signoretti S, Chiaur DS, Pagano M \& Loda M. Loss or altered subcellular localization of p27 in Barrett's associated adenocarcinoma. Cancer Research 199815 1730-1735.

12 Kawamata N, Morosetti R, Miller CW, Park D, Spirin KS, Nakamaki T, Takeuchi S, Hatta Y, Simpson J, Wilcyznski S, Lee YY, Bartam CR \& Koeffler HP. Molecular analysis of the cyclindependent kinase inhibitor gene p27/Kip1 in human malignancies. Cancer Research 199555 2266-2269.

13 Kossatz U \& Malek NP. p27: Tumor suppressor and oncogene...? Cell Research 200717 832-833. (doi:10.1038/cr.2007.86)

14 Lindberg D, Akerström G \& Westin G. Mutational analysis of p27 (CDKN1B) and p18 (CDKN2C) in sporadic pancreatic endocrine tumors argues against tumor-suppressor function. Neoplasia 2007 9 533-535. (doi:10.1593/neo.07328)

15 Ponce-Castañeda MV, Lee MH, Latres E, Polyak K, Lacombe L, Montgomery K, Mathew S, Krauter K, Sheinfeld J, Massague J et al. p27Kip1: chromosomal mapping to $12 \mathrm{p} 12-12 \mathrm{p} 13.1$ and absence of mutations in human tumors. Cancer Research 1995 55 1211-1214.

16 Pietenpol JA, Bohlander SK, Sato Y, Papadopoulos N, Liu B, Friedman C, Trask BJ, Roberts JM, Kinzler KWRowley JD et al. Assignment of the human p27Kip1 gene to $12 \mathrm{p} 13$ and its analysis in leukemias. Cancer Research 199555 1206-1210.

17 Stegmaier K, Pendse S, Barker GF, Bray-Ward P, Ward DC, Montgomery KT, Krauter KS, Reynolds C, Sklar J, Donnelly M, Bohlander SK, Rowley JD, Sallan SE, Gilliland DG \& Golub TR. Frequent loss of heterozygosity at the TEL gene locus in acute lymphoblastic leukemia of childhood. Blood 199586 38-44.

18 Hatta Y, Takeuchi S, Yokota J \& Koeffler HP. Ovarian cancer has frequent loss of heterozygosity at chromosome 12p12.3-13.1 (region of TEL and Kip1 loci) and chromosome 12q23-ter: evidence for two new tumour-suppressor genes. British Journal of Cancer 199775 1256-1262. (doi:10.1038/bjc.1997.214)

19 Hengst L \& Reed SI. Translational control of p27Kip1 accumulation during the cell cycle. Science 1996271 1861-1864. (doi:10.1126/science.271.5257.1861)

20 Pagano M, Tam SW, Theodoras AM, Beer-Romero P, Del Sal G, Chau V, Yew PR, Draetta GF \& Rolfe M. Role of the ubiquitin- proteasome pathway in regulating abundance of the cyclindependent kinase inhibitor p27. Science 1995269 682-685. (doi:10.1126/science.7624798)

21 Chiappetta G, De Marco C, Quintiero A, Califano D, Gherardi S, Malanga D, Scrima M, Montero-Conde C, Cito L, Monaco M, Motti ML, Pasquinelli R, Agosti V, Robledo M, Fusco A \& Viglietto G. Overexpression of the S-phase kinase-associated protein 2 in thyroid cancer. Endocrine-Related Cancer 200714 405-420. (doi:10.1677/ERC-06-0030)

22 Viglietto G, Motti ML \& Fusco A. Understanding p27(kip1) deregulation in cancer: down-regulation or mislocalization. Cell Cycle 20021 394-400. (doi:10.4161/cc.1.6.263)

23 Motti ML, De Marco C, Califano D, Fusco A \& Viglietto G. Aktdependent T198 phosphorylation of cyclin-dependent kinase inhibitor p27kip1 in breast cancer. Cell Cycle 20043 10741080. (doi:10.4161/cc.3.8.1073)

24 Min YH, Cheong JW, Kim JY, Eom JI, Lee ST, Hahn JS, Ko YW \& Lee MH. Cytoplasmic mislocalization of p27Kip1 protein is associated with constitutive phosphorylation of Akt or protein kinase $\mathrm{B}$ and poor prognosis in acute myelogenous leukemia. Cancer Research 200464 5225-5231. (doi:10.1158/0008-5472. CAN-04-0174)

25 Fero ML, Rivkin M, Tasch M, Porter P, Carow CE, Firpo E, Polyak K, Tsai LH, Broudy V, Perlmutter RM, Kaushansky K \& Roberts JM. A syndrome of multiorgan hyperplasia with features of gigantism, tumorigenesis, and female sterility in p27(Kip1)-deficient mice. Cell 199685 733-744. (doi:10.1016/S0092-8674(00)81239-8)

26 Kiyokawa H, Kineman RD, Manova-Todorova KO, Soares VC, Hoffman ES, Ono M, Khanam D, Hayday AC, Frohman LA \& Koff A. Enhanced growth of mice lacking the cyclin-dependent kinase inhibitor function of p27(Kip1). Cell 199685 721-732. (doi:10.1016/S0092-8674(00)81238-6)

27 Nakayama K, Ishida $\mathrm{N}$, Shirane $\mathrm{M}$, Inomata $\mathrm{A}$, Inoue $\mathrm{T}$, Shishido N, Horii I, Loh DY \& Nakayama K. Mice lacking p27(Kip1) display increased body size, multiple organ hyperplasia, retinal dysplasia, and pituitary tumors. Cell 199685 707-720. (doi:10.1016/S0092-8674(00)81237-4)

28 Fero ML, Randel E, Gurley KE, Roberts JM \& Kemp CJ. The murine gene p27Kip 1 is haplo-insufficient for tumour suppression. Nature 1998396 177-180. (doi:10.1038/24179)

29 Kwon TK, Nagel JE, Buchholz MA \& Nordin AA. Characterization of the murine cyclin-dependent kinase inhibitor gene p27Kip1. Gene 1996180 113-120. (doi:10.1016/S0378-1119 (96)00416-7)

30 Zhang Y \& Lin SC. Molecular characterization of the cyclindependent kinase inhibitor p27 promoter. Biochimica et Biophysica Acta 19971353 307-317.

31 Ito E, Iwahashi Y, Yanagisawa Y, Suzuki Y, Sugano S, Yuasa Y \& Maruyama K. Two short sequences have positive effects on the human p27Kip1 gene transcription. Gene $1999 \mathbf{2 2 8}$ 93-100. (doi:10.1016/S0378-1119(99)00022-0)

32 Livak KJ \& Schmittgen TD. Analysis of relative gene expression data using real-time quantitative PCR and the 2(-Delta Delta C(T)) method. Methods 20014 402-408. (doi:10.1006/meth. 2001.1262)

33 Millard SS, Vidal A, Markus M \& Koff A. A U-rich element in the $5^{\prime}$ untranslated region is necessary for the translation of p27 mRNA. Molecular and Cellular Biology 200020 5947-5959. (doi:10. 1128/MCB.20.16.5947-5959.2000)

34 Kullmann M, Göpfert U, Siewe B \& Hengst L. ELAV/Hu proteins inhibit p27 translation via an IRES element in the p27 $5^{\prime}$ UTR. Genes and Development 200216 3087-3099. (doi:10.1101/gad. 248902)

35 Minami S, Ohtani-Fujita N, Igata E, Tamaki T \& Sakai T. Molecular cloning and characterization of the human p27Kip1 gene promoter. FEBS Letters 1997411 1-6. (doi:10.1016/S00145793(97)00660-1)

36 Coleman J, Hawkinson M, Miskimins R \& Miskimins WK. The major transcription initiation site of the p27Kip1 gene is conserved in human and mouse and produces a long 5'-UTR. BMC Molecular Biology 20012 12. (doi:10.1186/1471-2199-2-12) 
37 Miskimins WK, Wang G, Hawkinson M \& Miskimins R. Control of cyclin-dependent kinase inhibitor p27 expression by capindependent translation. Molecular and Cellular Biology 200121 4960-4967. (doi:10.1128/MCB.21.15.4960-4967.2001)

38 Coleman J \& Miskimins WK. Structure and activity of the internal ribosome entry site within the human p27 Kip1 5'-untranslated region. RNA Biology 20096 84-89. (doi:10.4161/rna.6.1.7572)

39 Liu Z, Dong Z, Han B, Yang Y, Liu Y \& Zhang JT. Regulation of expression by promoters versus internal ribosome entry site in the $5^{\prime}$-untranslated sequence of the human cyclin-dependent kinase inhibitor p27kip1. Nucleic Acids Research 200533 3763-3771. (doi:10.1093/nar/gki680)

40 Mathews DH, Sabina J, Zucker M \& Turner H. Expanded sequence dependence of thermodynamic parameters provides robust prediction of RNA secondary structure. Journal of Molecular Biology 1999 288 911-940. (doi:10.1006/jmbi.1999.2700)
41 Gruber AR, Lorenz R, Bernhart SH, Neuböck R \& Hofacker IL. The Vienna RNA websuite. Nucleic Acids Research 20081 W70-W74. (doi:10.1093/nar/gkn188)

42 Franklin DS, Godfrey VL, O’Brien DA, Deng C \& Xiong Y. Functional collaboration between different cyclin-dependent kinase inhibitors suppresses tumor growth with distinct tissue specificity. Molecular and Cellular Biology 200020 6147-6158. (doi:10.1128/MCB.20.16.6147-6158.2000)

43 Marx SJ. Molecular genetics of multiple endocrine neoplasia types 1 and 2. Nature Reviews. Cancer 20055 367-375. (doi:10.1038/ nrc1610)

Received 14 August 2011

Revised version received 22 November 2011

Accepted 30 November 2011 